\title{
EFFECT OF PROCESSING VARIABLES ON THE MICROSTRUCTURE AND MECHANICAL PROPERTIES OF MICROPOROUS CARBON MATERIALS
}

M. Singh , R.F. Dacek, NYMA, Inc., Lewis Research Center Group, Cleveland, OH 44135, msingh@lerc.nasa.gov

\section{ABSTRACT}

Microporous carbon materials with different pore and strut sizes have been fabricated by the pyrolysis of furfuryl alcohol resin, triethylene glycol, and p-toluene sulfonic acid mixtures. The resulting materials were characterized by scanning electron microscopy and density measurements. The room temperature flexural strength and modulus of these materials decreases with increasing amount of acid curing agent.

\section{INTRODUCTION}

Processing and product development activities on microporous carbon materials have attracted a great deal of attention in recent years. The potential applications of these materials include catalyst support, adsorbents, molecular sieves, porous electrodes and other battery components [1-3]. These materials have amorphous (glassy) or graphitic structures. Glassy carbon materials are produced by the pyrolysis of a variety of highly cross-linked polymers $[1,6]$. In transition from resin to glassy carbon during pyrolysis, pores are developed due to the evolution of gases. Hucke [7] has developed an approach to fabricate porous glassy carbon materials using pore formers. Based on this approach, a variety of microporous carbon materials with controlled porosity and carbon strut sizes have been fabricated and characterized [8].

It is well known that the microstructure formed during the pyrolysis of pure resins has significant influence on the mechanical properties of glassy carbon materials [9-11]. The carbon produced by the pyrolysis of pure resins has porous networks with irregular pores. The mechanical properties of porous carbon depends on the properties of starting resin and the pyrolysis conditions.

The objective of this paper is to study the effect of the acid content on the microstructure and density of microporous carbon materials. Flexural strength and modulus of materials with different acid contents have been determined.

\section{EXPERIMENTAL PROCEDURE}

Four types of microporous carbon materials were made from mixtures of furfuryl alcohol resin, triethylene glycol, and p-toluene sulfonic acid (PTSA) curing agent. The amount of resin $(72 \mathrm{~g})$ and glycol $(90 \mathrm{~g})$ was kept constant in all the specimens. The amount of acid curing agent was $7,10,14$, and $20 \mathrm{~g}$ and these specimens were denoted as $A, B, C$, and $D$, respectively. These materials were fabricated in plate form $\left(3^{\prime \prime} \times 4^{\prime \prime} \times 0.2^{\prime \prime}\right)$. The resin mixtures were cast into a glass mold and cured at $60{ }^{\circ} \mathrm{C}$. The pyrolysis was carried out by heating up to $700^{\circ} \mathrm{C}$ which yields the microporous carbon 
material. An schematic of the fabrication process is shown in Fig. 1.

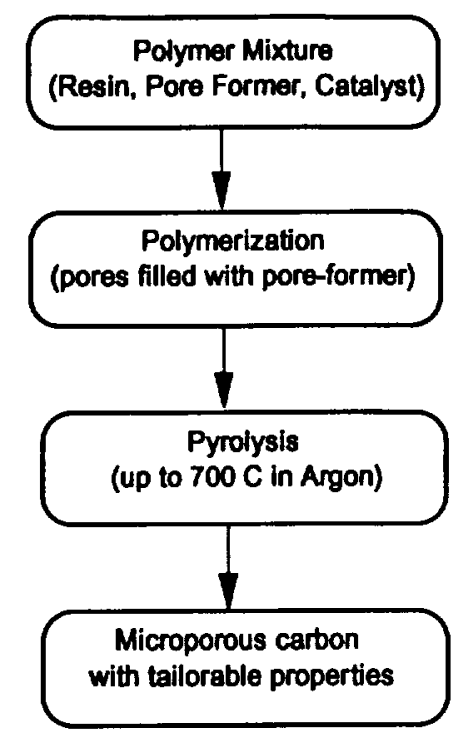

Fig. 1: Schematic of the microporous carbon fabrication process.

Microstructural characterization of the preforms was carried out on a Jeol-JSM 35 scanning electron microscope. The physical density was determined by measuring the dimensions and weight of the sample. Room temperature flexural properties of the specimens were measured using three-point bend tests ( $40 \mathrm{~mm}$ span) with a crosshead speed of $1.27 \mathrm{~mm} / \mathrm{min}$. Five specimens of each type were tested for mechanical properties. Modulus was calulated from the three-point flexural curves.

\section{RESULTS AND DISCUSSION}

\section{Microstructure and Density}

Four types of microporous carbon materials, denoted as A, B, C, and D, with similar amounts of resin and glycol contents were fabricated. The effect of varying acid catalyst content on the densities of these materials are given in Table 1. It is clearly evident from Table 1 that with increasing amounts of acid in the resin mixture, the density of the final material decreases. Scanning electron micrographs of the fracture surfaces of these materials are shown in Fig. 2. The micrograph of specimen A shows a homogeneous distribution of pores and irregular shaped carbon struts. Specimens B and C show a combination of irregular and spherical struts while specimen $D$ shows spherical struts with some oval shaped struts. The strut size of specimen $D$ is smaller than other materials and it has highest amount of porosity. 
It is interesting to note the differences in the microstructure and density of specimens with increasing acid content. At this point, all the scientific reasons for this behavior are not completely understood. One possible contributing factor is the acceleration of the polymerization induced phase separation process with higher amounts of acid catalysts which effects the nucleation and growth of the carbonaceous skeleton. Further studies are in progress and will be reported elsewhere [12].

Table 1. Effect of amount of acid catalyst on the density of microporous carbon materials.

\begin{tabular}{|c|c|c|}
\hline Specimen & Amount of Catalyst (g) & Density $\left(\mathbf{g} / \mathbf{c m}^{\mathbf{3}}\right)$ \\
\hline A & 7 & 0.81 \\
\hline B & 10 & 0.71 \\
\hline C & 14 & 0.69 \\
\hline D & 20 & 0.65 \\
\hline
\end{tabular}

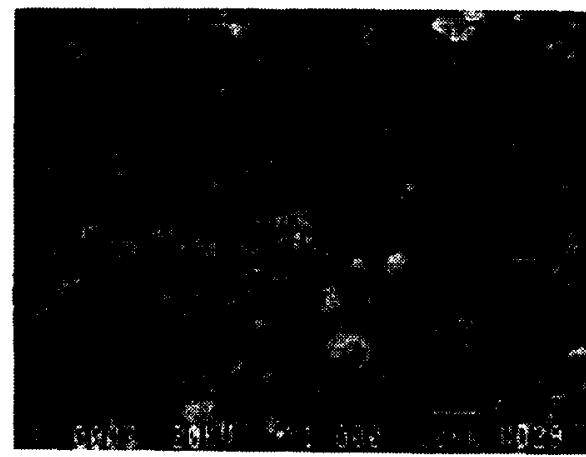

A

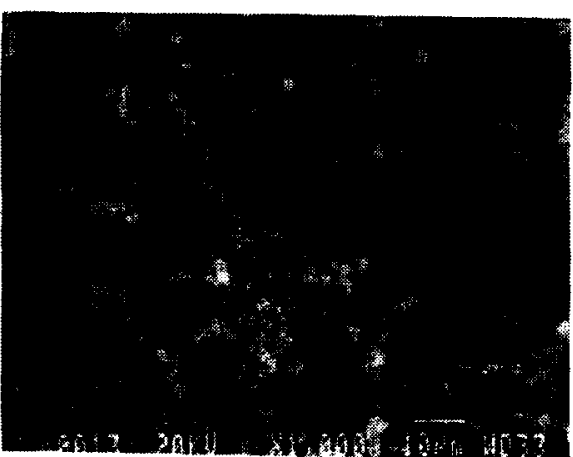

C

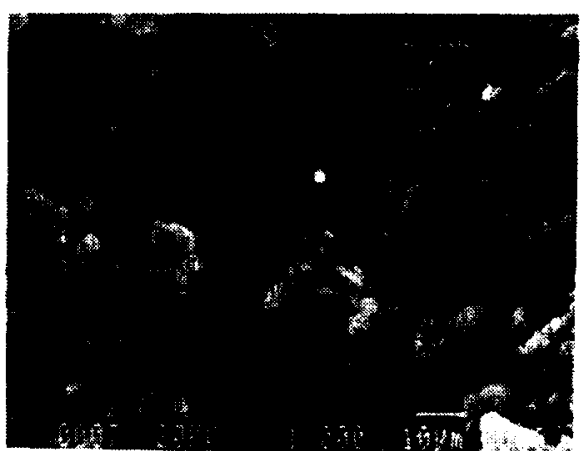

B

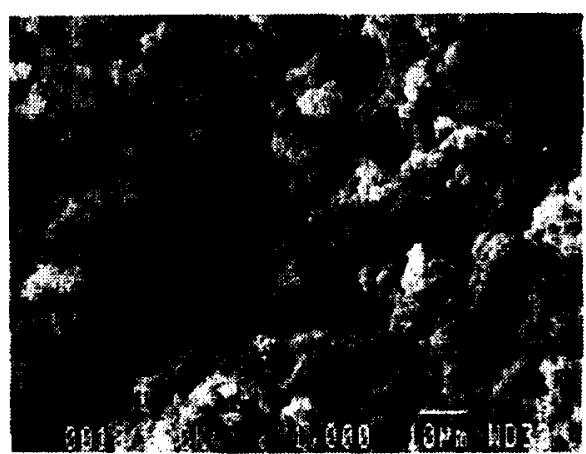

D

Fig. 2: Micrographs showing the fracture surfaces of specimens A, B, C, and D. 


\section{Mechanical Properties}

Flexural strength and modulus of specimen A, B, C, and D are given in Table 2. The flexural strength of these materials decreases with increasing amount of acid in the starting mixtures. The strength drop from specimen $A$ to $D$ is $\sim 40 \%$. There is a similar trend in the elastic modulus data for these specimens where the moduls drop from specimen $A$ to $D$ is $\sim 56 \%$. The reduction in mechanical properties parallels the decrease in the density of these materials.

Table 2. Flexural strength and modulus of microporous carbon materials.

\begin{tabular}{|c|c|c|}
\hline Specimen & $\begin{array}{c}\text { Flexural Strength } \\
\text { (MPa) }\end{array}$ & Modulus (GPa) \\
\hline A & $10.5 \pm 1.9$ & $3.7 \pm 0.26$ \\
\hline B & $8.2 \pm 1.1$ & $2.5 \pm 0.42$ \\
\hline C & $8 \pm 0.71$ & $2.2 \pm 0.12$ \\
\hline D & $6.3 \pm 0.5$ & $1.6 \pm 0.13$ \\
\hline
\end{tabular}

\section{CONCLUSIONS}

It has been demonstrated that the microporous carbon materials with different densities and strut sizes can be fabricated by the pyrolysis of furfuryl alcohol resin, triethylene glycol, and p-toluene sulfonic acid mixtures. The densities, flexural strengths, and modulus of these materials decreases with increasing amount of acid curing agent.

\section{REFERENCES}

1. G.M. Jenkins and K. Kawamura, 'Polymeric Carbons', Cambridge University Press, Cambridge, UK (1976).

2. L.J. Gibson and M.F. Ashby, 'Cellular Solids - Structure and Properties', Pergamon Press, New York (1988).

3. E.T. Turkdogan, R.G. Olsson, and J.V. Vinters, Carbon, 8 (1970) 545.

4. H.C. Foley, Microporous Materials, 4 (1995) 407.

5. J.H. Aubert and A.P. Sylwester, J. Mater. Sci., 26 (1991) 5741. 
6. E. Fitzer, K. Mueller, and W. Schaefer, in 'Chemistry and Physics of Carbon', Vol. 7, P.L. Walker, Jr., Ed., Marcel Dekker Inc., New York, (1971) 237.

7. E.E. Hucke, US Patent 3, 859, 421 (1975).

8. M. Singh and S.C. Farmer, in "Microporous and Macroporous Carbon Materials", Materials Research Society Proceedings, Pittsburgh, PA (1996) submitted.

9. C.R. Choe and K.H. Lee, Carbon, 30, 2 (1992) 247.

10. Z. Lausevic and S. Marinkovic, Carbon, 24 (1986) 575.

11. J. Rautavuori and P. Tormala, British Patent No. 1597938, Sept. 1981.

12. M. Singh, Unpublished work (1996). 
